\title{
Acute Spinal Cord Compression in Hereditary Multiple Exostoses: Case Report
}

\author{
S. Tuncer, MD, ${ }^{1}$ I. Erden, $M D,{ }^{2}$ N. Aydin, $M D,{ }^{3}$ D. Öge, $M^{3}$ \\ ${ }^{1}$ Department of Physical Medicine and Rehabilitation, ${ }^{2}$ Department of Radiodiag- \\ nosis, ${ }^{3}$ Department of Neurology, University Hospital of Ankara, Turkey.
}

\begin{abstract}
Summary
A case of hereditary multiple exostoses with spinal cord compression by a costal exostosis is reported in a 12-year-old boy. Paraplegia is an unusual complication of hereditary multiple exostoses. In the patient with spinal cord signs, the offending exostoses should be defined with appropriate roentgenograms and myelographic and CT scanning investigations.
\end{abstract}

Key words: Spinal cord compression; Hereditary multiple exostoses; Paraplegia; Diaphyseal aclasis.

The entity of hereditary multiple exostoses (hereditary deforming dyschondroplasia; multiple cartilaginous exostoses, multiple osteochondromatosis; diaphyseal aclasis) is the most common dysplasia of bone encountered in clinical practice (Jaffe, 1958). The lesions arise in any bone preformed in cartilage and particularly affects long bones with a predilection for the ends of the diaphyses. Neurological complications are uncommon but when present, are usually due to pressure on peripheral nerves by the bony growths. Spinal cord compression by an exostosis is an unusual complication of this disease, with only 26 cases reported in the literature up to 1983 (Buur, 1983). The disorder progresses throughout the growth period and often becomes clinically manifest during adolescence when rapid growth occurs.

\section{Case report}

A 12-year-old boy was admitted to the University Hospital in Ankara (Ibn-i Sina Medical Center) with a 2 months history of progressive weakness in his legs. He had bed rest with a diagnosis of possible rheumatic arthritis. Two weeks before admission his legs became numb. One week before admission he began to have constant dribbling of urine. The family history revealed that the parents were cousins. 


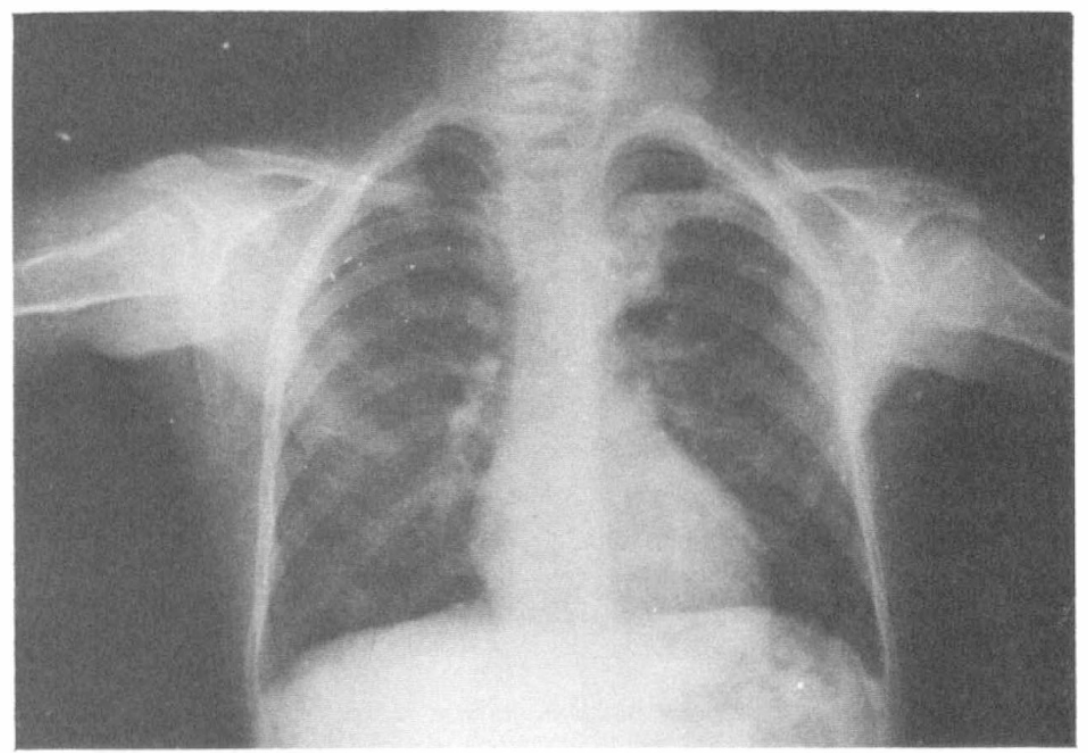

Figure 1 Anteroposterior roentgenogram of the lung. The widening of a rib and a mass of exotoses are present near the left $\mathrm{T} 4$ and $\mathrm{T} 5$ vertebrae.

On examination, the patient was alert and co-operative. His blood pressure was $100 / 60$ $\mathrm{mm} \mathrm{Hg}$, pulse 88 per minute and temperature $36.5^{\circ} \mathrm{C}$. There were bony masses in the second phalanxes of the median digits bilaterally, in the fifth ribs in the midclavicular line bilaterally; on the medial aspect of the left knee, above and below the joint; on the proximal region of the right arm; in the left forearm and in the left wrist. There was a spastic paraplegia with hyperactive tendon reflexes; ankle clonus, Babinski sign and sensory deficit bilaterally. He was hyponesthetic from the T4-5 level. There was urgency of micturation.

A skeletal survey showed multiple exostoses involving both tibias, humeri, ribs, phalanges, radii and ulna (Fig. 1). Myelography demonstrated a posterior extradural defect at the T4-5 level (Fig. 2). Computed tomography showed a $3 \times 5 \mathrm{~cm}$ shaped tumour of bony density arising from the posterior medial arch of the left sixth rib, expanding the T5 foramen and compressing the spinal cord at the same level (Fig. 3).

Laminectomy of T3, T4 and T5 was performed, with exposure of the tumour arising from the posterior surface of the sixth rib on the left side. After removing the tumour, it was noted that the dural sac bulged posteriorly and pulsated normally. The patient continues with the rehabilitation and is doing well. He is now walking with the aid of crutches.

\section{Discussion}

The entity of hereditary multiple exostoses was first described by Stanley in 1849 (Jaffe, 1958). The metaphyseal regions of tubular long bones are most frequently involved, although exostoses may arise from any bone preformed in cartilage. A family history is present in approximately $60 \%$, the mode of inheritance being autosomal dominant with an equal sex distribution (Solomon, 1964). In some published series the disease is more frequent and more severe in males than in females (Krooth et al., 1961). 


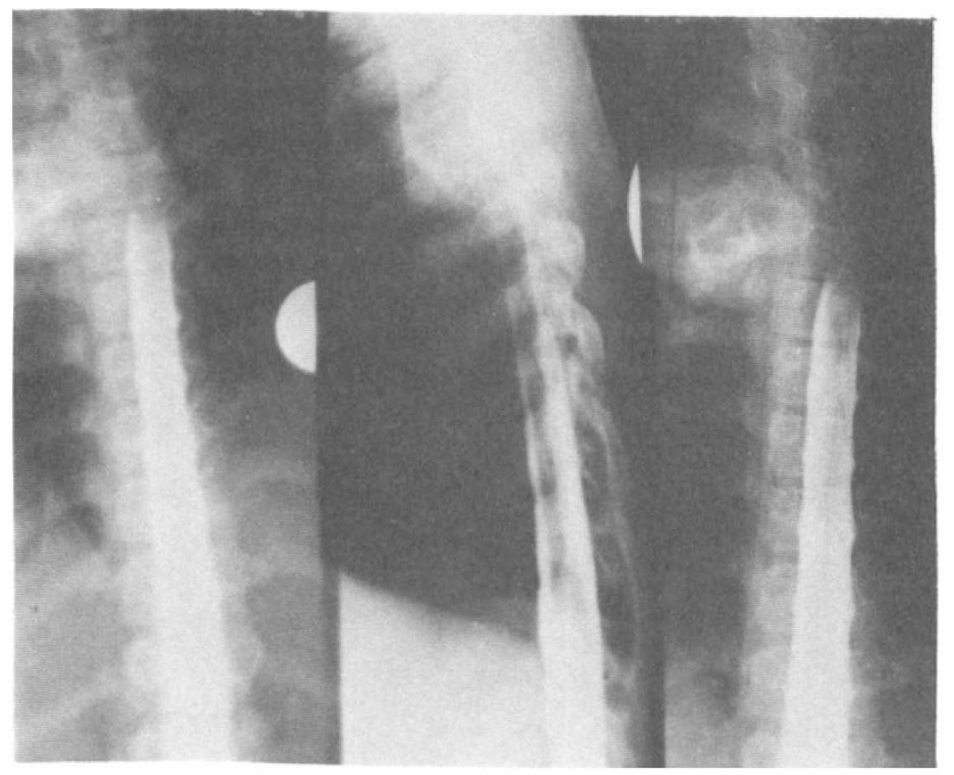

Figure 2 Myelogram confirming the location of the bony mass which compresses the cord at the T5-6 level. Exostoses can be seen on the rib

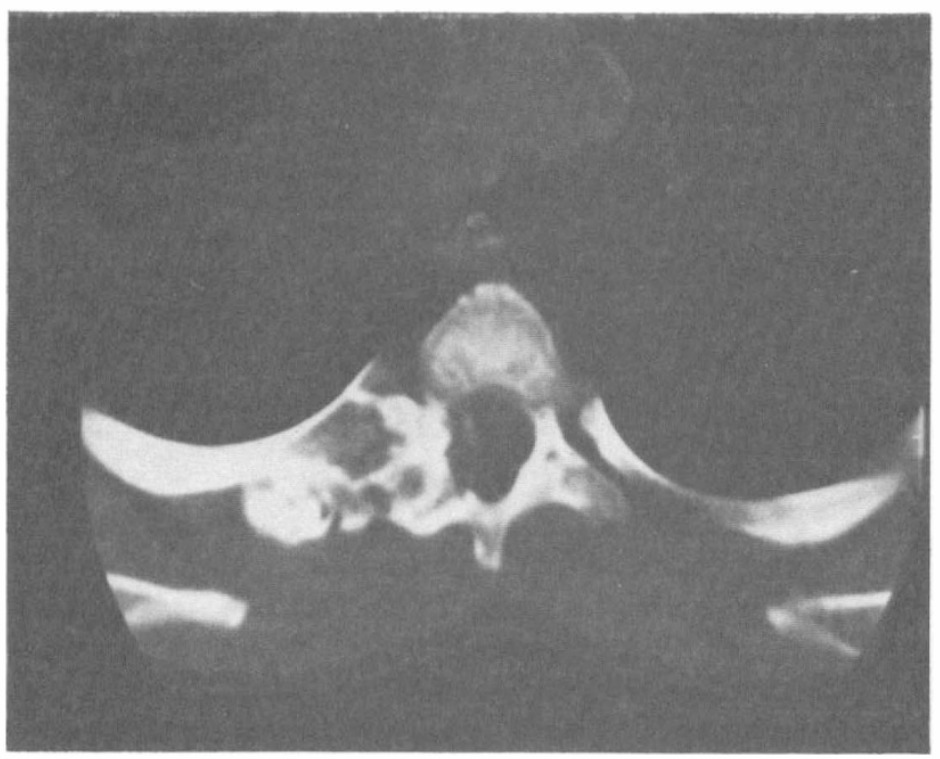

Figure 3 CT scan through T6 showing an exostosis compressing the spinal cord arising from the left sixth thoracic rib.

Neurological complications are uncommon and, when present, are usually due to pressure on peripheral nerves by the bony growths. The frequency of involvement of the spine was reported as $7 \%$ and $1 \%$ (Gökay, 1955; Carmel, 1968), but associated spinal cord compression is rare (Vinstein, 1971). The 
majority of recorded cases have involved the spinal cord in the thoracic and lumbar area but may occur at any level. A fatal outcome is particularly likely with high cervical lesions (Chiurco, 1970).

Routine X-ray studies are not usually adequate to determine the site of origin or the size of the tumour. Tomography is invaluable. Myelography is recommended to reveal the actual size of the tumour, since the cartilage cap of the bony exostosis is radiolucent (Palmer, 1980). To determine the origin of the tumour, CT scanning is valuable. In our case, the CT scan provided all of the preoperative information that was required. There are two special features in our patient, not previously mentioned in the literature: the acute onset of paraplegia, and compression of the spinal cord by tumour arising from a rib. The acute onset may be related to the age of our patient.

Successful removal produces excellent clinical results in the majority of cases.

\section{References}

BuUR T, MORCH MM 1983 Hereditary multiple exostoses with spinal cord compression (letter). fournal of Neurology, Neurosurgery and Psychiatry 46:98-98.

Carmel PW, Cramer FJ 1968 Cervical cord compression due to exostosis in patient with hereditary multiple exostoses. Fournal of Neurosurgery 28:500-503.

Chiurco AA 1970 Multiple exostoses of bone with fatal spinal cord compression. Report of a case and brief review of the literature. Neurology 20:275-278.

GöKAY H, BUCY PC 1955 Osteochondrome of the lumbar spinal: report of a case. Fournal of Neurosurgery 12:72-78.

JAFFE HL 1958 Tumors and Tumorous Conditions of the Bones and Joints. Lea and Febiger, Philadelphia.

KROOTH RS, MACkLIN MT, Hilbich TF 1961 Diaphyseal aclasis (multiple exostoses) on Guam. American fournal of Human Genetics 13:340-347.

PALmer FJ, Blum PW 1980 Osteochondroma with spinal cord compression: Report of three cases. Fournal of Neurosurgery 52:842-845.

Solomon L 1964 Hereditary multiple exostoses. American fournal of Human Genetics 16:351363.

Vinstein AL, Franken EA Jr 1971 Hereditary multiple exostoses: Report of a case with spinal cord compression. American fournal of Roentgen 112:405-407. 